\title{
Adaptive Web Applications for Citizens' Education. Case Study: Teaching Children the Value of Electrical Energy.
}

\author{
I. Moisil, S. Dzitac, L. Popper, A. Pitic
}

\section{Ioana Moisil, Alina Pitic}

Lucian Blaga Univeristy of Sibiu, Romania

E-mail: im25sibiu@gmail.com

\section{Simona Dzitac, Laurentiu Popper}

University of Oradea, Romania

E-mail: simona.dzitac@gmail.com, director@perfect-service.ro

\begin{abstract}
:
"The foundation of every state is the education of its youth."

Diogenes Laertius
\end{abstract}

Long-term energy saving and reduction of environmental consequences of energy consuming are among the most challenging objectives of our time. People are prone to routine and habit. To change these habits is almost a Sisif's work. In spite of continuous efforts from environmental specialists, we are witnessing an increase in electricity (and gas) consumption, at least at the level of households. Studies carried on have shown that consumers have in many cases an irrational behaviour. To correct that, researchers are studying consumers' decision making behaviour and try several intervention measures. In our paper we are presenting the design and development of a web based adaptive system aimed to educate citizens for an electrical energy saving behaviour. The system is composed of three subsystems: adaptation system, user's profile and knowledge base. We have used a user-centered design approach. For adults, users' profiles are build taking into account age group, educational level, gender, income, professional aspects, consuming behaviour. A set of questionnaires have been designed in order to collect users' data. For children, the standard profiles are more complicated and, in function of the age group, can be obtained off line through interviews or/and through online activities (games, quizzes etc.). The knowledge base is build for the electrical energy domain. The adaptation sub-system will present information to the user based on s/he profile. The system is populated with data for users of 6 to 10 years of age. For this users group a social and affective interaction design approach was used.

Keywords: adaptive web, electrical energy saving, citizens education, interaction design, user-centred design.

\section{Introduction}

The European Union (EU) has established that reducing energy consumption and eliminating energy wastage are among the main goals to be achieved in the near future. "At the end of 2006, the EU pledged to cut its annual consumption of primary energy by 20\% by 2020. To achieve this goal, it is working to mobilise public opinion, decision-makers and market operators and to set minimum energy efficiency standards and rules on labelling for products, services and infrastructure". [1]

It seems more than natural, in the information society, to use the web as a mean to make people aware of the energy saving problem. In fact there are many web sites informing about the ways of reducing energy consumption [1-6]. 
Analysing the content of these web presentations we have found out that though very informative and scientifically correct, they are not always answering to some users' expectations, being too serious, and too boring. This was the opinion of $56 \%$ of 200 users of age 6 to 22 investigated in 2009. It is clear that different actors that have a word to say in the process of reducing energy consumption must be approached in different ways.

It is also important to note that it is a problem of changing the behaviour, the mentality and this is a very sensitive process. Having this in mind we have tried to design and develop of a web based adaptive system aimed to educate citizens for an electrical energy saving behaviour. The system is composed of three subsystems: adaptation system, user's profile or model and knowledge base (domain model). We have used a user-centered design approach. For adults, users' profiles are built taking into account age group, educational level, gender, income, professional aspects, consuming behaviour.

A set of questionnaires have been designed in order to collect users' data. For children, the standard profiles are more complicated and, in function of the age group, can be obtained off line through interviews or/and through online activities (games, quizzes etc.). The knowledge base is build for the electrical energy domain. The adaptation sub-system will present information to the user based on $\mathrm{s} /$ he profile. At present the system is populated with data for users of 6 to 10 years of age.

\section{Design Considerations}

In our paper we are presenting a first case study with the educational software for electrical energy saving. The case study is considering users of 6 to 10 years of age. For this category of users we had use a hybrid user-centred design methodology, blending different kinds of usercentred designs with interaction (social interaction, affective interaction) and participatory design and taking into account learning objectives and learners age and preferences.

The design research phase had two steps. Firstly we identified the need of computerbased educational products, the interest of the users towards computers, the level of satisfaction concerning other computer-based educational products, what characteristics of human-computer interaction they prefer (sounds, colours, mediating agents) and also the general level of computer literacy. We have also investigated users' behaviour towards the educational/formative software market (are they buying educational software, if so, on what subjects, who is the buyer, how often, etc.). The second step aimed to investigate users' behaviour towards electrical energy consumption aspects (how interested they are, did they know what is electricity, how they perceive other educational software on this topic, are their parents concerned by energy saving, etc). 130 young pupils from both rural and urban locations participated in the design. $63 \%$ were girls and $37 \%$ boys, the age interval being from 6 to 10 years old. $84 \%$ had a computer at home. $82 \%$ have Internet connexion.

- Children in the first and forth grade (6 years old and 10 years old) are at the beginning of an educational cycle and therefore more exposed to change, with distributed interests and less interested than the others ( $50 \%$ are satisfied by the use of computers in class).

- $75 \%$ of the subjects that have a computer at home are very interested in using an educational software, but only $40 \%$ of those that do not have a computer at home showed a maximum interest.

- $86 \%$ of the subjects prefer computer games and $80 \%$ like also cartoons, movies, etc.; $66 \%$ of the girls choose stories and only $43 \%$ of the boys; attraction to music is growing with the age, from $60 \%$ at the age of 6 to $85 \%$ at the age of 10 .

- Most parents are restricting children access to Internet.

- Interest to something new is decreasing with age, from $93 \%$ at the age of 7 to $33 \%$ at the age of 11 . 
- The influence of the family environment is very important.

- $27 \%$ of the subjects voted for a software based mediator agent.

- $94 \%$ of the subjects prefer software with sound incorporated.

- For $57 \%$ of the subjects software products are provided by parents, $27 \%$ are buying themselves these products.

- $87 \%$ of the children do not know the most important sources of electrical energy ("electricity is coming from the cable").

- $73 \%$ of the subjects appreciate the idea of quizzes on how to save electrical energy.

- Children with intellectual parents are more aware of the aspects concerning energy saving especially linked to global warming. Children from rural area are more concerned by the cost of energy than by global warming. Some of them are thinking that this is not their problem.

- $76 \%$ of the subjects are attracted by computers.

Based on these results it has been decided how to design the software interface and how to structure the content. The software has to use the children' preferred colours, to have sound facilities, to enable the use of the mouse but also of the keyboard, the concepts introduced have to be transparent, the children being able to navigate freely through the software, games have to be included in order to make more attractive the product and less boring, if the case, and the mediator has to be included in the software.

All these data have been obtained during working meetings with the children. For example, we have discussed the video-clip Energy, let's save it! [1]. The video-clip has been found attractive by children 8 to 10 years of age. For the others it was not interesting. One observation was that "it goes too quickly". In fact the video clip is presenting in less than 4 minutes a global view of energy waste in the day by day activities. The presentation is user-friendly, in an attractive way and it raises worries, but no more.

Another observation, concerning a different web application was that "it sounds like papa!" (Citing: "Don't leave lights on when no one is in the room. If you are going to be out of the room for more than five minutes, turn off the light." [2]). So it was very clear that the site must be designed taking into account the children preferences.

As a result we have structured the web application in four main chapters:

1. What is Electricity

a. Short history

b. Experiments

c. Sources of electrical energy

i. Classical

ii. Alternative

2. Using and saving Electrical Energy

3. Games, activities, quizzes, puzzles, enigmas

4. Resources for teachers, parents and educators

The system architecture is composed of three subsystems: adaptation system, user's profile or model and knowledge base (domain model).

The domain model for electrical energy is a set of concepts, each concept consisting of a set of topics. Topics are linked to each other thus forming a semantic network. A topic is presented usually on a web page. A page is divided in sub-pages (chunks) that will differ in function of the user type [7-9]. The adaptation module is providing different interfaces and contents in function of the user profile (model). For the moment each page has implemented two variants: user in the age group 6 to 10, and children older than 10 years.

We have used plants and trees images ant the beginning because these were interesting for children of all ages (fig.2) 


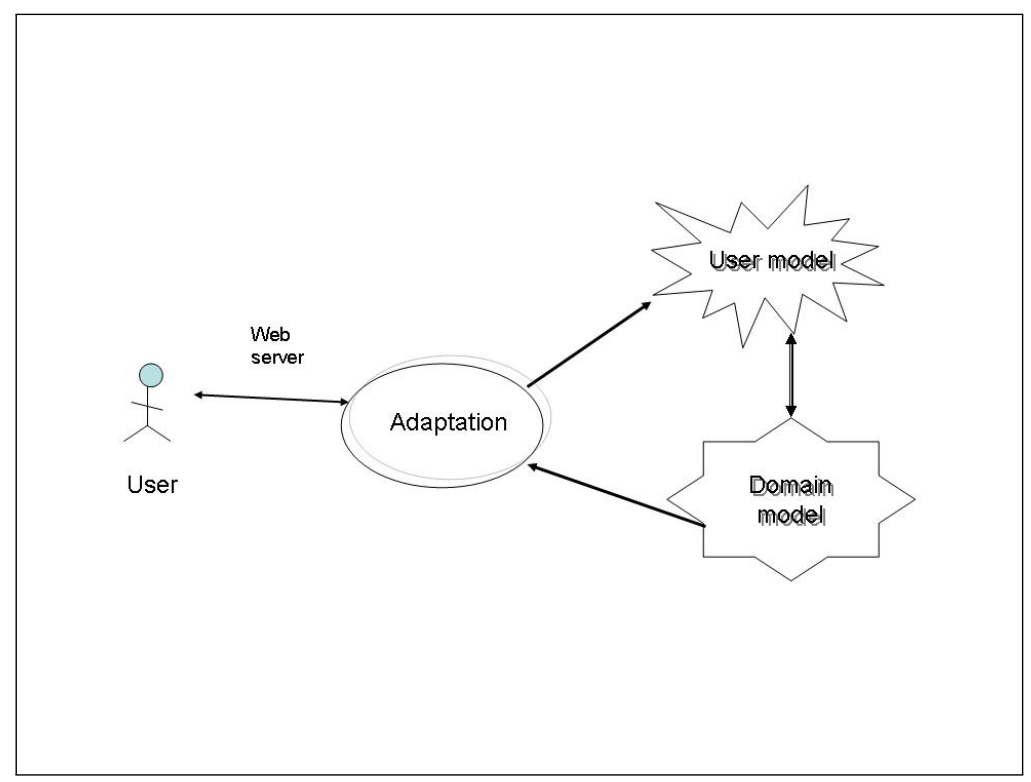

Figure 1: System architecture.

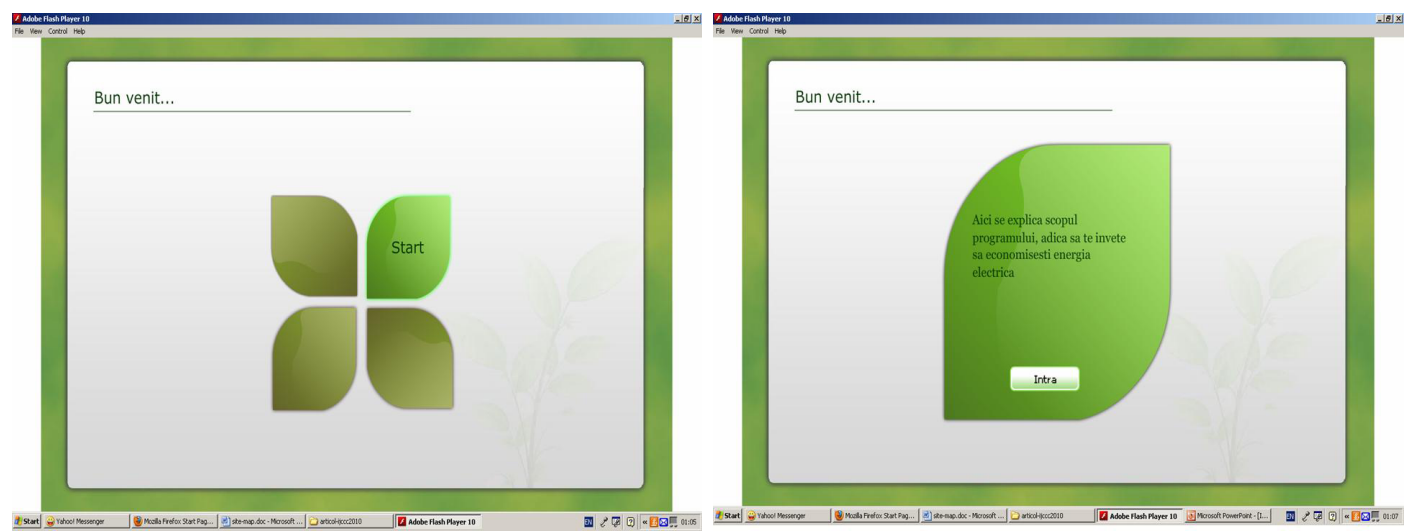

Figure 2: and $2 \mathrm{~b}$. Accessing the web application

The user is identified by a user name and a password. This is in fact the link to the user profile.

The user can freely navigate in the site but also s/he can choose a certain topic looking at the icons on the screen. For example in fig.4 there several icons (buttons) giving access to information on electrical energy sources. Each button is also explained by voice.

The children can experience the effect of using too much light (fig.5 and 6). 


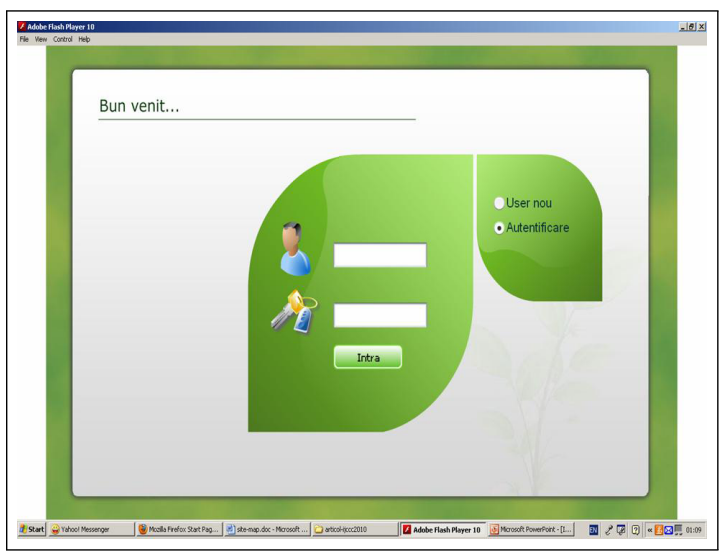

Figure 3: Access to the web application.

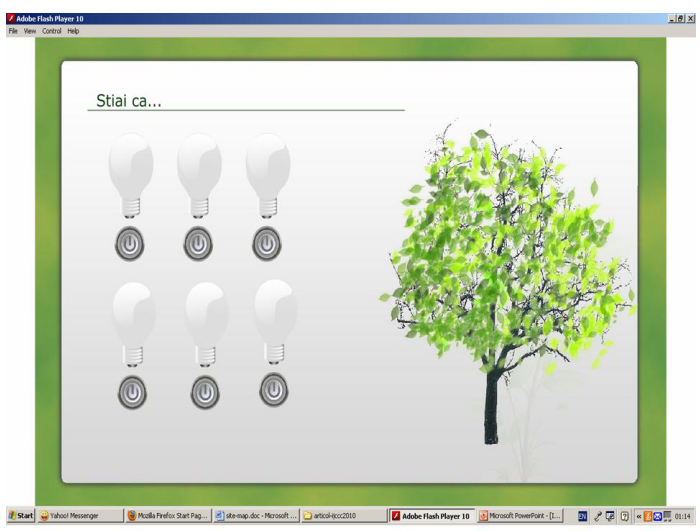

Figure 5: All electrical bulbs are off (the tree has all leaves)

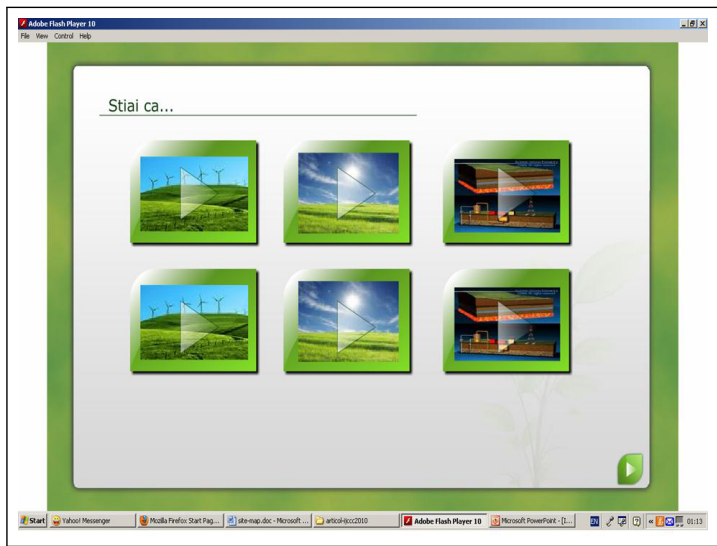

Figure 4: Buttons giving access to information on electrical energy sources.

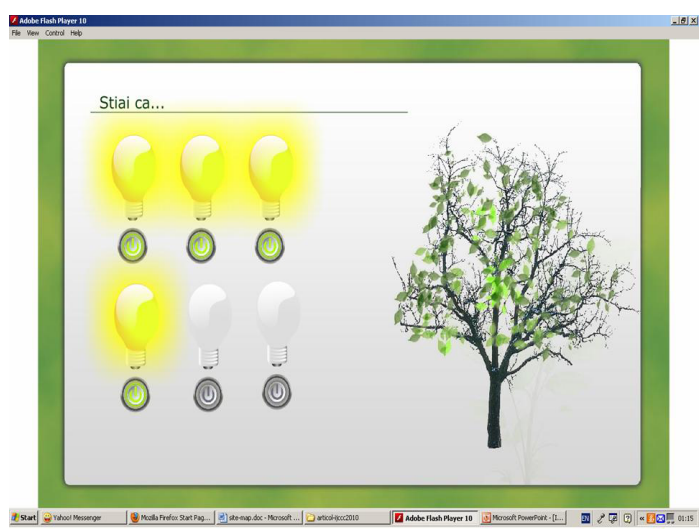

Figure 6: Four electrical bulbs are on (the tree has lost most of the leaves)

The client is implemented as Web pages. There is a number of linked frames. We have used Flash, PHP, MySQL and JavaScript language that made possible to overcome HTML limitations.

\section{Evaluation}

The current interface has been evaluated from the point of view of presentation aspects and functionalities by the children participating in the design and also by other 34 children ( 6 to 11 years of age). $92 \%$ were very satisfied with the web application. $7 \%$ would have liked more games and $1 \%$ declared that he is not interested in the subject. Two teachers and two parents participated also in the evaluation process. The first appreciation was positive.

\section{Conclusion and Further Research}

In this paper we have described the design and development of an Adaptive Webbased System for citizens' education in respect to electrical energy consumption reduction. The system is a complex one. The core system is implemented and also several modules.

We had presented a first case study with the educational software for electrical energy saving. The case study is considering users of 6 to 10 years of age. For this category of users we had use a hybrid user-centred design methodology, blending different kinds of user-centred designs with interaction (social interaction, affective interaction) and participatory design and taking into 
account learning objectives and learners age and preferences. The results of the first evaluations were positive.

Future research will continue to develop the system with other users' profiles (other age category, in the first stage) and to evaluate the educational effectiveness of the system's adaptation.

\section{Bibliography}

[1] http://ec.europa.eu/energy/efficiency/index_en.htm.

[2] http://www.energyquest.ca.gov/saving_energy/index.html.

[3] http://tonto.eia.doe.gov/kids/energy.cfm?page=3.

[4] http://www.kyotoinhome.info/.

[5] www.eais.info.

[6] Thttp://www.oppapers.com/subjects/energy-saving-page1.html.

[7] Ayersman, D.J. \& Minden, A.V. (1995). Individual differences, computers, and instruction. Computers in Human Behavior, 11(3-4), 371-390.

[8] Brusilovsky, P.(1996). Methods and Techniques of Adaptive Hypermedia. User Modeling and User-adapted Interaction. 6, 87-129.

[9] Jonassen, D. \& Wang, S. (1993). Acquiring structural knowledge from semantically structured hypertext. Journal of Computer-based Instruction, 20(1), 1-8.

[10] Liu, Y., Ginther, D. (1999). Cognitive Styles and Distance Education. On-line Journal of Distance Learning Administration, 2,3.

[11] C.Y. Huang, T.T. Yang, W.L Chen, S. Y. Nof, Reference Architecture for Collaborative Design, Int. J. of Computers, Communications \& Control, ISSN 1841- 9836, E-ISSN 18419844 Vol. V (2010), No. 1, pp. 71-90.

[12] Antonios Andreatos, Virtual Communities and their Importance for Informal Learning International Journal of Computers, Communications \& Control, Vol. II (2007), No. 1, pp. $39-47$. 